\title{
Epidemiology and management of osteoporosis in the People's Republic of China: current perspectives
}

This article was published in the following Dove Press journal:

Clinical Interventions in Aging

25 June 2015

Number of times this article has been viewed

\author{
Xiao Lin' \\ Dan Xiong' \\ Yi-Qun Peng' \\ Zhi-Feng Sheng' \\ $\mathrm{Xi}-\mathrm{Yu} \mathrm{Wu}^{\prime}$ \\ Xian-Ping $\mathrm{Wu}^{\prime}$ \\ Feng $\mathrm{Wu}^{2}$ \\ Ling-Qing Yuan' \\ Er-Yuan Liao' \\ 'Institute of Metabolism and \\ Endocrinology, ${ }^{2}$ Department \\ of Pathology, The Second Xiangya \\ Hospital, Central South University, \\ Changsha, Hunan, People's Republic \\ of China
}

\begin{abstract}
With the progressive aging of the population, osteoporosis has gradually grown into a global health problem for men and women aged 50 years and older because of its consequences in terms of disabilities and fragility fractures. This is especially true in the People's Republic of China, which has the largest population and an increasing proportion of elderly people, as osteoporosis has become a serious challenge to the Chinese government, society, and family. Apart from the fact that all osteoporotic fractures can increase the patient's morbidity, they can also result in fractures of the hip and vertebrae, which are associated with a significantly higher mortality. The cost of osteoporotic fractures, moreover, is a heavy burden on families, society, and even the country, which is likely to increase in the future due, in part, to the improvement in average life expectancy. Therefore, understanding the epidemiology of osteoporosis is essential and is significant for developing strategies to help reduce this problem. In this review, we will summarize the epidemiology of osteoporosis in the People's Republic of China, including the epidemiology of osteoporotic fractures, focusing on preventive methods and the management of osteoporosis, which consist of basic measures and pharmacological treatments.
\end{abstract}

Keywords: osteoporosis, fracture, epidemiology, management

\section{Introduction}

Osteoporosis (OP) can be defined as a systematic skeletal disorder characterized by low bone mass and the microarchitectural deterioration of bone tissue, with a consequent increase in the fragility of bone and susceptibility to fracture. OP can be classified into two main categories: primary OP and secondary OP. The former can occur in both males and females of all ages, but it often occurs in postmenopausal women; it also happens later in life in men. By contrast, secondary OP is the result of medication use (glucocorticoid, immunosuppressant), disease (Cushing's syndrome, hyperparathyroidism), other conditions (vitamin D deficiency and hypogonadism), and so on. ${ }^{1}$ Nowadays, OP has become a serious problem throughout the world. ${ }^{2}$ In developed countries, for example, the prevalence rate of OP in older adults was about $13 \%-18 \%$ and $21.2 \%$ in the United States and Sweden, respectively. ${ }^{3,4}$ In the People's Republic of China, however, the mean prevalence of OP in older adults is estimated at $15.7 \%$, and it is considered to be increasing gradually with the increasing age of the total population, which is associated with the improvement of the average life expectancy. Since there were about 202.43 million people aged 60 years and older in the People's Republic of China at the end of 2013, ${ }^{5}$ the People's Republic of China will carry a large proportion of the financial burden of OP. Moreover, because of the family planning policy in the People's Republic of China, the ratio of older people is likely to increase significantly in the coming years.

\footnotetext{
Correspondence: Ling-Qing Yuan; Er-Yuan Liao Institute of Metabolism and Endocrinology, The Second Xiangya Hospital, Central South University, No 139 Middle Renmin Road, Changsha, Hunan 4I00II, People's Republic of China Email allenylq@hotmail.com; eyliao@2Icn.com
}

submit your manuscript $\mid$ www.dovepress.com 
Osteoporotic fracture related to $\mathrm{OP}$ is also a huge global problem. The main categories of osteoporotic fracture are: hip fracture, vertebral fracture, and distal forearm fracture. There are also other bone sites where osteoporotic fractures appear (tibia, ribs, pelvis, humerus, clavicle, fibula, etc). The cost of osteoporotic fracture, especially hip fracture, is so huge that it will have an impact on many families. Therefore, OP has received much attention in many countries of the world. ${ }^{6,7}$

For the management of OP, there are two types of methods. One includes basic measures such as physical exercise, changing to a healthy lifestyle, quitting smoking, supplementation of calcium and vitamin $\mathrm{D}$, and so on. The other type is pharmacological treatment, and the two main categories available so far for treating $\mathrm{OP}$ are antiresorptives and anabolic drugs. ${ }^{8,9}$ However, Chinese herbal medicine is an alternative choice that is very popular in the People's Republic of China. Therefore, this review will summarize the epidemiology and treatment of OP in the People's Republic of China.

\section{Definition of OP}

The definition of OP can be defined in three different ways. The medical definition is that OP is a skeletal disease characterized by low bone mass, microarchitectural deterioration of bone tissue with an increase in fragility of bone, and a tendency to fracture easily. The most widely used method is the clinical definition proposed by the World Health Organization (WHO) in 1994, which is defined as bone mineral density (BMD) measurements in women that have fallen by more than 2.5 standard deviations (SDs) below the young average value. ${ }^{10}$ In addition, pain, kyphosis, loss of height, and a history of fragility fracture are used as operational definitions of OP. ${ }^{11}$ Therefore, in defining OP, it is important to consider both the strength of the bone and risk of fractures.

\section{Diagnosis of OP}

A clinical diagnosis should be made of individuals who sustain a low-trauma or fragility fracture. Currently in the
People's Republic of China, the most commonly used method for the diagnosis of OP is established by measuring BMD by dual-energy X-ray absorptiometry (DEXA) according to WHO diagnostic criteria. ${ }^{12,13}$ Based on the T-scores derived from BMD measurements of the total hip or neck of femur, the diagnosis is classified as normal, osteopenia, or OP (Table 1). ${ }^{10,14}$ However, for economic reasons, only the big hospitals in large cities such as Beijing, Shanghai, and some provincial capitals are equipped with DEXA equipment, which hinders the diagnosis, prevention, and treatment of OP. Research conducted in Beijing validated the OP Selfassessment Tool for Asians (OSTA) as a simple and effective tool for identifying primary OP in postmenopausal Han Chinese women. It is a calculator based on the age and body weight using the following formula:

[body weight $(\mathrm{kg})-$ age $($ year $)] \times 0.2 .{ }^{15}$

\section{Epidemiology of OP in the People's Republic of China}

The People's Republic of China has a population of more than 1.398 billion, which is $18.84 \%$ of the world's population. ${ }^{16}$ Though the annual rate of growth has dropped from 1.69\% in 1996 to $1.20 \%$ at present, ${ }^{17}$ the population will continue to increase gradually with the improvement of residents' living conditions, increased average life expectancy, and the development of a social health care system. People older than 60 years accounted for $6.10 \%$ of the population in 1964 and $10.97 \%$ (about 130 million people) at the end of the 20th century; according to the Sixth National Population Census of the People's Republic of China, it was $13.26 \%$ (about 177 million) in 2010, with those older than 65 years accounting for $8.87 \%$ of the population. Recently published data indicates that $15 \%$ (202.43 million) are older than 60 years in $2013 .{ }^{18}$ Furthermore, this percentage is anticipated to reach $25 \%$ (about 400 million) by $2050 .{ }^{19}$ Because of this, it has been estimated that the population with $\mathrm{OP}$ will increase sharply from 83.9 million in 1997 to 212 million by $2050 .{ }^{19}$

Table I World Health Organization criteria for the diagnosis of osteoporosis

\begin{tabular}{ll}
\hline Diagnosis categories & Definitions \\
\hline Normal & BMD within I SD of the young adult mean value $(T$-score $\geq-I .0)$ \\
Osteopenia & BMD $>$ I SD below the young adult mean, but $<2.5$ SD below this value $(-2.5<\mathrm{T}$-score $<-I .0)$ \\
Osteoporosis & BMD $\geq 2.5$ SD below the young adult mean value $(T$-score $\leq-2.5)$ \\
Severe (established) osteoporosis & BMD $\geq 2.5$ SD below the young adult mean value $(T$-score $\leq-2.5)$ and in the presence of $\geq I$ \\
& fragility fractures
\end{tabular}

Note: Data from World Health Organization Study Group, ${ }^{10}$ and Kanis et al. ${ }^{14}$

Abbreviations: BMD, bone mineral density; SD, standard deviation. 
All of this makes OP a major public health problem in the People's Republic of China.

There are regional differences in the distribution of OP in the People's Republic of China. A survey by Li et $\mathrm{al}^{20}$ was conducted in five areas of the People's Republic of China including the north (Jilin), south (Guangdong), east (Shanghai), northeast (Beijing), and southwest (Chengdu), which involved 5,593 Chinese of Han nationality selected by the stratified multistep cluster sampling method in 2002 . BMD was measured and questionnaires was taken among people aged over 40 years and it was found that the prevalence rates of $\mathrm{OP}$ (in descending order) are as follows: Jilin (15.1\%); Shanghai (14.2\%); Chengdu (11.3\%); Guangdong (10.2\%); and Beijing (5.2\%). The differences might be due to environmental, nutritional, and genetic factors. In our previous study, the relationship between body composition and fracture risk using the Fracture Risk Assessment (FRAX) model in an urban sample of central south Chinese postmenopausal women showed that $37.5 \%$ suffered from OP. ${ }^{21}$

OP is mainly found in females. Epidemiologic studies have indicated that the incidence of OP in females aged 50-59 years have increased by $50 \%{ }^{22}$ A large-scale study in Europe showed that OP affected only 3\%-6\% of men over 50 years old, but over $30 \%$ of women. ${ }^{2}$ What is more, the gradient with which prevalence increases with age is steeper for females. ${ }^{2}$ This phenomenon can also be seen in the People's Republic of China. A survey conducted in Hefei in the People's Republic of China showed that the ratio of females to males with OP is 1.61:1.0. ${ }^{23}$ Most cases of OP occur in postmenopausal women, and the incidence increases with age..$^{24,25}$ The main reasons why women are at a higher risk of OP are as follows: 1) the speed of bone loss in women after menopause is much more rapid than in men because of a significant decrease in estrogen; and 2) women have a longer life expectancy than men. ${ }^{19}$ In recent years, however, the prevalence and effects of OP in men has aroused the attention of researchers and health care professionals as the population ages, and up to $25 \%$ of men aged over 50 years will experience OP. Moreover, men had less knowledge of OP than women. ${ }^{26,27}$ One study that investigated Chinese male's knowledge of OP in Macau observed that the group of men aged over 55 years scored significantly lower than women, according to the Osteoporosis Knowledge Assessment Tool (OKAT).$^{28}$ This result is in accordance with a study conducted in Hong Kong..$^{29}$ Supposedly, the situation in Mainland China should be similar. Unfortunately, suffering any osteoporotic fracture leads to a higher mortality rate in men than in women. ${ }^{30,31}$ Therefore, it is time to highlight the care of men's health; in connection with this, our team has established BMD reference databases for the diagnosis and evaluation of OP in the men of central southern China, which is important and useful for the detection of OP in men. ${ }^{32}$ There have been few large-scale studies or surveys on male OP sufferers in Mainland China, and it is necessary and urgent to attach importance to men's bone health as well as women's.

\section{Importance of osteopenia}

Osteopenia occurs as the precursor of OP when BMD $\mathrm{T}$-scores are between -2.5 and -1.0 , according to the WHO diagnostic standard. ${ }^{14}$ About 64.6\% ( 11.35 million) of women and $57.6 \%$ (10.04 million) of men aged 50 years or older experienced osteopenia according to statistical data from the National Health and Nutrition Examination Survey for the years 2005-2006. ${ }^{18}$ Unlike the prevalence of OP in men, over $30 \%$ of men aged 50 years or older have osteopenia, which is just a little lower compared to the prevalence of OP in women. The prevalence of osteopenia, however, increases more quickly with age among elderly men compared to women. ${ }^{33}$ Furthermore, it often takes several years for osteopenia to transition to OP, sometimes just 1 year for individuals with rapid severe bone loss osteopenia, and it can also lead to fragility fractures causing physical limitations, substantial morbidity, mortality, hospital care, and so on. ${ }^{34}$ In the People's Republic of China, there has been hardly any research studying the prevalence of osteopenia and its influence on populations. There was a survey about the prevalence of osteopenia in elderly patients with psychiatric disorders in Huzhou, People's Republic of China, which showed that the prevalence of osteopenia was $33.3 \%$ and that male patients had a higher rate of osteopenia than females $(42.1 \%$ versus $28.1 \%$, respectively). ${ }^{35}$ The reason for this phenomenon may be that most females developed OP (53.1\% versus $5 \%)$, whereas a substantial proportion of males suffered from osteopenia. It is necessary and important to discover and even predict the risks of osteopenia, since the majority of fractures actually take place in osteopenic subjects. Because of that, the patients may be treated and preventive steps can be taken earlier to greatly decrease the rate of morbidity and mortality related to osteoporotic fractures.

\section{Epidemiology of osteoporotic fracture}

Osteoporotic fracture, one of the most severe complications of OP, is prevalent among the elderly population with OP. It is considered to be a fracture from low-energy trauma 
that is defined as a fall from a standing height or less, or a trauma that would not give rise to fracture in a healthy individual. ${ }^{36}$ OP causes more than 8.9 million fractures annually worldwide - approximately 1,000 cases per hour. ${ }^{37}$ In the People's Republic of China, the risk of osteoporotic fractures $(40 \%)$ in women is higher than the sum of the incidence of breast cancer, endometrial cancer, and ovarian cancer, while in men (at 13\%), it is higher than the risk of prostate cancer. ${ }^{38}$ A cross-sectional and population-based study conducted in Shanghai showed that the prevalence of osteoporotic fractures in the elderly was $15.9 \%$ in females and $14.3 \%$ in males. ${ }^{39}$ A large national study in Beijing found that the prevalence of fractures was $26.6 \% .^{40}$ In rural areas, the total prevalence rate of OP among the population over 60 years old was $8.83 \%,{ }^{18}$ and a rate of $14 \%$ was reported in a local study of Chongqing City. ${ }^{41}$ In addition, there have been two studies related to fracture rates in Hong Kong: one reported that $30.4 \%$ of old men had at least one low-trauma fracture, ${ }^{42}$ while the other reported that the rate of a history of fractures among those over 50 years old was just $6.6 \% .{ }^{43}$ The differences in the study samples and data collection methods may explain the huge discrepancy. The BMD measured by DEXA is the gold criterion for OP diagnosis, and it is the most available predictor of fracture in clinical practice. The risk of osteoporotic fracture increases constantly, as BMD T-scores decline from -1.5 to $-3 \mathrm{SD}^{44}$ that is to say, the lower the BMD, the higher risk of fracture will be.

$\mathrm{BMD}$, however, is not the only risk factor in fracture, since fracture can also happen in the absence of OP, ${ }^{45}$ maybe because of deterioration of bone quality. It is well known that bone strength is measured by both BMD and bone quality. Also, fall risk and other clinical risk factors are important in fracture prediction. Another tool for predicting the risk of fracture is the FRAX model, developed from the data of nine cohorts around the world, which uses clinical risk factors, with or without BMD, to compute the 10-year probability of hip fracture or a major osteoporotic fracture. ${ }^{46}$ In Asia, there are different intervention thresholds within FRAX algorithms for some Asian countries and regions. Hong Kong researchers recommend using the Caucasian risk profile to calculate the absolute fracture risk for Hong Kong subjects. ${ }^{47}$ However, when we use FRAX to estimate the 10-year risk of hip fracture in Chinese mainland women, the predicted fracture probability in Chinese mainland women was much lower than that for United Kingdom or Hong Kong Chinese women. Based on our previous study, ${ }^{48}$ we have suggested that intervention in terms of both BMD testing and treatment should be recommended for individuals with a 10 -year probability of major osteoporotic fracture that exceeded $4.0 \%$ or a 10 -year probability of hip fracture that exceeded $1.3 \%$. Since osteoporotic fractures characteristically occur in the areas of the skeleton with high amounts of trabeculae, the most common types of osteoporotic fractures are vertebra fractures. The other two common types of osteoporotic fractures are hip and distal forearm fractures, all of which have their own respective characteristics. Other sites for osteoporotic fractures, including the tibia, pelvis, clavicle, ribs, and so on, have also received special attention in recent years. ${ }^{6,7}$ The financial and health burden of osteoporotic fractures, especially hip fractures, is enormous in the People's Republic of China because of the size of the population. One study examined the health care costs of osteoporotic fractures in a hospital in Shanghai during 2002-2004 and found that the average hospital stay was almost 1 month, and the average total cost was around RMB 12,000 (about USD 1,929). ${ }^{49}$ A similar phenomenon had been found in the Chinese capital, Beijing. ${ }^{50}$ In fact, these data just reflect the cost and burden of osteoporotic fracture 10 years earlier. With the aging population and changes in people's lifestyle, both the number of OP cases and its complications (in terms of osteoporotic fracture) are coupled with a rapid increase in the total costs. ${ }^{51}$ Next, we will discuss the epidemiology and characteristics of the three main categories of osteoporotic fracture.

\section{Hip fracture}

Hip fracture is most likely to be a fatal result of OP, with devastating and expensive consequences because it causes both significant morbidity and excess mortality. The total annual number of hip fractures is expected to rise from 1.3 million in 1990 to 2.6 million by 2025 , and 4.5 million by 2050 worldwide. ${ }^{52}$ Asia accounted for almost half of this number, most notably in the People's Republic of China. ${ }^{53,54}$ Surveys conducted in Beijing, ${ }^{55}$ Shenyang, ${ }^{56}$ and Tangshan ${ }^{57}$ 20 years ago showed that the rates of hip fracture were 88.0, 67.2 , and 12 cases per 100,000 women and 97.0, 80.8, and 25 cases per 100,000 men, respectively. The results of all three researches are very interesting, revealing that in the age range from 50 to 55 years, the incidence of hip fracture is higher in men than in women. This probably indicates that males of that age group mainly suffer from severe force fractures related to trauma.

The incidence of hip fractures, however, increases in both males and females with increasing age, especially in females. For instance, there was a dramatic increase in the incidence of hip fractures in the population of Tangshan by $85 \%$ in men and $306 \%$ in women from that in 1994 , based on 
the data from the Sixth National Population Census (2010). ${ }^{57}$ The female to male ratio reversed to 1.03:1.0. ${ }^{58}$ Analogously, the average annual number of hip fractures in people older than 50 years, according to the Beijing Ministry of Health, increased from 479 to 2,423 in women and from 441 to 1,586 in men between 1990 and 2004. In other words, the rates for those aged 50 years or older increased by $58 \%$ in women and $49 \%$ in men. ${ }^{59}$ Similar trends can also be seen in other areas of the People's Republic of China including Taiwan, ${ }^{60}$ Chongqing, ${ }^{41}$ and Hefei. ${ }^{23}$ The growth rate of osteoporotic fractures in urban women and men was $3.34 \%$ and $3.85 \%$, respectively, and the same rates were $3.36 \%$ and $1.00 \%$ for rural areas between 2002 and 2006. It is expected on this basis to reach 626 per 100,000 men and 1,444 per 100,000 women by 2050 . That is to say, there will be 5.91 million hip fractures in 2050 in the People's Republic of China. ${ }^{18}$ In fact, the number of hip fractures is more than that in the People's Republic of China since hip fractures in rural areas, the vast majority of patients with hip fracture choose to rest at home instead of receiving surgical treatment due to economic reasons, which leads to the underreporting of hip fractures. ${ }^{18}$ These results may relate to the fact that there is a larger number of women with OP than men, and that women have a rapid loss of bone after menopause. Furthermore, the number of hip fractures and its incidence will keep on increasing with the aging population, the development of urbanization, and the changing lifestyle of people who are less likely to walk and engage in outdoor exercise and instead rely more on cars and buses. ${ }^{38}$ Though severe trauma accounted for a high proportion of total hip fractures, the vast majority, however, followed a fall from standing height or less in both men and women who have low bone strength. ${ }^{61}$ But in Hong Kong, the age-adjusted incidence rate of hip fracture among people aged 65 years or older decreased from 381.6 per 100,000 men and 853.3 per 100,000 women in 2001 to 341.7 and 703.1 by 2009 , respectively, ${ }^{62}$ a trend that has also been observed in Western countries. ${ }^{63}$ This trend might be replicated in Mainland China in the future, with increased awareness and knowledge of OP, the development of the economy, and improvements of the medical insurance system.

Osteoporotic hip fractures have numerous adverse outcomes and result in high mortality among the elderly population. A person who has survived hip fracture usually exhibits decreased mobility, impaired quality of life, more dependence on family, and increased demand for medical caregivers and social services, as well as a substantial physical, mental, and financial burden. ${ }^{64-66}$ The rate of disability is up to $50 \%$ and the mortality is as high as $15 \%-33 \%$ in the 1st year after hip fracture. ${ }^{18,67}$ What is worse is that about $28 \%$ of females and $37.5 \%$ of males die by the 2 nd year. ${ }^{68}$

Among all types of osteoporotic fractures in the People's Republic of China, the cost of hip fractures is the highest. A prospective study of the economic burden of osteoporotic fractures in Western China showed that the annual total costs of hip fracture was RMB 27,283 (or USD 4,386) per personyear, followed by vertebral fracture (RMB 21,474, or USD 3,452 ). The annual rate of increase in cost is about $6 \%$, and it is estimated that it will be five times of that by 2050 , when the total cost for the whole country will reach RMB 1,800 billion (USD 288 billion). ${ }^{18}$ Yet, the patients' average self-declared family income was only RMB 2,307 \pm 548 (or USD 371 \pm 88 ) per month..$^{51}$ The majority of the cost is associated with direct medical care costs because the average hospital stay for hip fracture is about 22-24 days. However, the nonmedical direct costs and indirect costs also cannot be ignored. The long hospitalization makes patients prone to develop acute complications including bronchopneumonia and urinary tract infections, which occupy more medical resources. ${ }^{69}$ Therefore, an osteoporotic fracture is a considerable burden, not only on the individual and family, but also on the health service system and on the whole society in the People's Republic of China. Hence, understanding the etiology and risk factors for OP is important and significant in the prevention of hip fracture. Further research is needed to find new prevention methods and new therapies for hip fractures.

\section{Vertebral fracture}

Despite being the most common complication of OP, accounting for almost $50 \%$ of all osteoporotic fractures, vertebral fractures have received less attention compared to hip fractures. ${ }^{70}$ The transition site between the more rigid and more flexible part of the spine and the mid part of the kyphotic region of the thoracic spine are the common sites of vertebral fractures. ${ }^{71}$ Although vertebral fractures are often coupled with back pain, height loss, and kyphosis, a large number of vertebral fractures are asymptomatic, and the difficulty in distinguishing the causes of these physical symptoms means that only $30 \%-40 \%$ vertebral fractures come to medical attention. ${ }^{72}$ The wedge fracture is the most common type of vertebral fracture. ${ }^{73}$ Nowadays, plain radiograph, computed tomography, and magnetic resonance imaging are the most common techniques for detecting vertebral fractures. ${ }^{74}$

Increasing age, increasing number of clinical risk factors, and decreasing BMD are related to the prevalence of vertebral fracture. Besides, the prevalence of vertebral 
fracture is increasing in association with aging. The prevalence of vertebral fractures is lower than $20 \%$ for people aged 50-69 years in Beijing, Chengdu, and Shanghai, and that of people aged $70-79$ years is $19 \%, 25.1 \%$, and $25.42 \%$, respectively. For people aged over 80 years, however, the prevalence of vertebral fractures is above $36 \%$ in all three cities. ${ }^{18}$ Approximately 18.1 million new vertebral fractures occur every year in the People's Republic of China, and it is estimated that the total number of vertebral fractures will reach 367.5 million in 2020 and 485.0 million by $2050 .^{18}$ Research on the prevalence of vertebral fractures in Beijing indicated an incidence of about 15\% among postmenopausal women, reaching $40 \%$ in women aged 80 years or older. ${ }^{75}$ About $22 \%$ of subjects aged over 45 years were found to have vertebral fractures in Hong Kong, South China. ${ }^{76}$ The incidence of vertebral fractures among Chinese women older than 65 years from Taiwan is $20 \%{ }^{77}$ This incidence is similar to that found in Caucasian women. ${ }^{78}$ For Chinese men aged over 50 years, the prevalence of vertebral fractures was about 14\%. Generally, the incidence of vertebral fractures is similar to, or slightly higher, in Chinese women than in men in all age groups. ${ }^{20}$

The clinical consequences of vertebral fracture include chronic disabling pain, spinal deformity with round kyphosis, pulmonary dysfunction, loss of mobility, gross impairment in activities of daily life, psychosocial disturbance (notably depression), and excess long-term mortality. ${ }^{79}$ The heavy financial burden brought about by vertebral fractures is another issue. The annual cost is USD 13.8 billion in the US, ${ }^{80}$ and SEK 4.6 billion (USD 0.71 billion) in Sweden. ${ }^{81}$ However, there is a lack of data on the cost of vertebral fractures in the People's Republic of China, but it is likely that the amounts involved would draw attention. Besides this, vertebral fracture is a risk factor for both future vertebral and nonvertebral fractures, such as hip fractures. ${ }^{82,83}$ Therefore, understanding the prevalence of vertebral deformities and the risk factors for vertebral fractures would help doctors to make appropriate decisions and focus their attention on the diagnosis and prevention of OP, since the majority of vertebral fractures are independent of falls and are clinically silent.

\section{Distal forearm fracture}

Distal forearm fracture has a different age distribution from vertebral or hip fractures. The incidence increases linearly from ages 40 to 65 years. ${ }^{84}$ This may be related to the patterns of falling with advancing age. In general, about one-half of cases are due to tripping or slipping; these may be the most frequent causes of falls among elderly patients. Another one-fifth are due to syncope, one-fifth to one-third are due to a loss of balance, and the remainder are the result of miscellaneous factors. ${ }^{85}$ In men, however, the incidence rates stay relatively constant between the ages of 20 years and 80 years. The female to male ratio is about $4: 1$. The most common type of distal forearm fractures is the Colles' fracture, mainly caused by falling outdoors. The peak incidence of distal forearm fractures often occurs in winter, particularly during periods of icy weather. ${ }^{86}$ Though less than $20 \%$ of distal forearm fracture patients are hospitalized, it does not appear to cause significant mortality compared with hip fractures $;{ }^{37}$ the influence of this should not be neglected. In women with a distal forearm fracture, the functions related to the upper extremity (meal preparation, heavy housekeeping, shopping) and social roles will be limited in the early period after injury, and their psychological health will also be impaired. ${ }^{87}$ In addition, the average cost of the 1 st year after distal forearm fracture was approximately RMB 8,828 (or USD 1,419) per person in the People's Republic of China between 2010 and 2012, ${ }^{51}$ and about $40 \%$ of the cost was for hospitalization. This characteristic is similar to that found in some developed countries. ${ }^{81,88,89}$ Nevertheless, very few studies have been published so far on the incidence of distal forearm fracture in the People's Republic of China, and it needs much more technical and financial resources to conduct a comprehensive and complete epidemiological survey due to the large population involved.

\section{Risk factors for OP}

Understanding the risk factors for OP is significant for several reasons: 1) it can help us to understand the pathophysiology of the disorder; 2) it can help in the treatment of individual patients; 3 ) it is available to support preventive strategies against OP and fractures; and 4) it can be helpful in decreasing the incidence of OP and fractures.

The risk factors for OP can be classified into different categories: general factors; body composition; lifestyle; dietary factors; genetic factors; and secondary factors (Table 2).

\section{General factors}

Females are more likely to have OP, since estrogen loss takes place rapidly after menopause. As age is the absolute risk factor for OP, with advancing age, the incidence of OP obviously increases. Some studies have indicated that weight is a protective factor for OP, since it can protect against fracture by cushioning and absorbing the impact of a fall, and given that it reduces the likelihood of hip fracture due to falls..$^{90,91,92}$ 
Table 2 Risk factors for osteoporosis

\begin{tabular}{|c|c|}
\hline Categories & Risk factors \\
\hline \multirow[t]{5}{*}{ General factors } & Female \\
\hline & Age \\
\hline & Height \\
\hline & Body mass index \\
\hline & History of fragility fracture \\
\hline \multirow[t]{2}{*}{ Body composition } & Fat mass \\
\hline & Lean mass \\
\hline \multirow[t]{2}{*}{ Dietary factors } & Vitamin D \\
\hline & Calcium \\
\hline \multirow[t]{4}{*}{ Lifestyle } & Sedentary or lack of exercise \\
\hline & Cigarette smoking \\
\hline & Alcohol drinking \\
\hline & Caffeine \\
\hline \multirow[t]{3}{*}{ Genetic factors } & OPG, RANK, RANKL \\
\hline & ESRI, LRP4, LRP5, BTB40, SOST \\
\hline & A family history of fracture \\
\hline \multirow[t]{6}{*}{ Medications } & Glucocorticoids \\
\hline & Immunosuppressants \\
\hline & Heparin \\
\hline & Anticonvulsants \\
\hline & Thiazolidenediones \\
\hline & Proton pump inhibitors \\
\hline \multirow[t]{4}{*}{ Diseases } & Endocrine disorders \\
\hline & Gastrointestinal diseases \\
\hline & Hematologic diseases \\
\hline & Other disorders \\
\hline
\end{tabular}

Our study, and another previous study, also showed that postmenopausal nonobese women with type 2 diabetes have a lower BMD and higher OP rate, ${ }^{93,94}$ but now, more surveys are confirming that high body mass index (BMI) is also a risk factor for OP, especially for the overweight population. Another risk factor is height: tall people have a greater risk of OP than shorter individuals. ${ }^{95}$

\section{Body composition}

Traditionally, body composition comprises fat mass and lean mass. Lean mass has been found to be positively associated with BMD at all bone sites, and it is a protective factor for OP. ${ }^{96}$ But the relationship between fat mass and OP is, however, controversial. ${ }^{97,98}$ There are different opinions about the different BMI levels and the distinct value criteria. ${ }^{99}$

\section{Dietary factors}

Vitamin D deficiency status has been defined as having serum 25-hydroxyvitamin D (25[OH]D) levels $<50 \mathrm{nmol} / \mathrm{L}$ (20 ng/mL). ${ }^{100}$ The People's Republic of China covers a large area, and regions at different latitudes receive different amounts of sunlight, but in almost every city, the phenomenon of insufficient vitamin D status is found, including in Beijing, ${ }^{101}$ Shanghai, ${ }^{102}$ Shenyang, ${ }^{103}$ Lanzhou, ${ }^{104}$ and even Hong Kong. ${ }^{105}$ Our recent nationwide cross-sectional multicenter study of serum 25(OH)D levels among postmenopausal women in the People's Republic of China demonstrated that vitamin D deficiency and insufficiency are common among postmenopausal women in the People's Republic of China, especially during the winter and among those living in urban areas. Our study recruited 1,688 women with a mean age of 65.4 years, and our results showed that $61.4 \%$ of these postmenopausal women had a serum $25(\mathrm{OH})$ D level $<20 \mathrm{ng} / \mathrm{mL}$. The overall prevalence was $91.2 \%$ for $25(\mathrm{OH}) \mathrm{D}<30 \mathrm{ng} / \mathrm{mL}$ and $37.6 \%$ for $25(\mathrm{OH}) \mathrm{D}<15 \mathrm{ng} / \mathrm{mL}{ }^{106}$ Many studies have shown that low vitamin D levels are associated with increased OP and fracture incidence. ${ }^{107-109}$

The main reasons for vitamin D deficiency are twofold: a lack of adequate exposure to sunlight; and shortage of a dietary vitamin D source. A Chinese diet based on plant proteins, apart from being low in calcium content, also lacks high vitamin D content. ${ }^{110}$

\section{Lifestyle}

It is well known that physical activity is beneficial to the skeleton, and that the restriction of physical activity and immobility lead to bone loss. ${ }^{111}$ However, with the economic development and improvement of people's living standards, a sedentary lifestyle that depends much more on cars and buses is popular among the Chinese, which is harmful to BMD. Moreover, mahjong is a very popular entertainment activity in the People's Republic of China, which results in long periods of sitting, even causing mahjong-related deep vein thrombosis. ${ }^{112}$ In addition, cigarette smoking, alcohol drinking, and high levels of caffeine intake can decrease BMD in women and men, thus increasing the risk of OP. ${ }^{113,114}$

\section{Genetic factors}

OP is a polygenetic disorder disease, and gene-gene interactions may play a key role in determining the risk of the disease. What is more, BMD is a highly heritable trait, with heritability estimated at $50 \%-80 \%{ }^{115}$ Several susceptibility genes for OP, including OPG, RANK, RANKL, ZBTB40, ESR1, LRP4, LRP5, MARK3, MHC, SPTBN1, and SOST, have been revealed. ${ }^{116,117}$ Moreover, six OP susceptibility genes (ESR1, LRP5, OPG, RANK, ZBTB40, and SOST) have been found to be associated with BMDs in a Han Chinese population, ${ }^{118}$ and Li et al ${ }^{119}$ found that GALNT3 plays a role in the genetic susceptibility to OP among Chinese postmenopausal women. Besides, a family history of fracture is also associated with an increased risk of OP and fracture in an older population, particularly in older women. ${ }^{120}$ 


\section{Secondary factors}

Factors causing secondary OP can be grouped into two categories: medications and diseases. Glucocorticoids are one of the most common medications to induce OP. ${ }^{121}$ Other medications consist of immunosuppressants, heparin, anticonvulsants, thiazolidinediones, proton pump inhibitors, and so on. ${ }^{122}$ Numerous diseases are known to cause bone loss and OP, including endocrine disorders (malnutrition, hyperthyroidism, hyperparathyroidism, Cushing's syndrome, hypogonadism), gastrointestinal diseases (primary biliary cirrhosis, Crohn's disease, hemochromatosis, inflammatory bowel disease, pancreatic diseases), hematologic diseases (multiple myeloma, systemic mastocytosis, leukemia, thalassemia, lymphoma), and other disorders (such as rheumatoid arthritis, stroke, depression). ${ }^{75,114}$

\section{Management of OP}

OP is a condition that is often asymptomatic or even "silent" until a fracture occurs. Fracture, consequently, is always associated with significant morbidity, mortality, and a heavy economic burden. Therefore, attaching more importance to preventing and detecting younger patients and selecting appropriate treatment for those who are already affected is important in the prevention of OPrelated fractures. Two kinds of methods are used in the People's Republic of China to decrease the risk of OP and its related effects: basic measurements and pharmacologic treatments. ${ }^{38,123}$

\section{Basic measurements}

Basic measurements are indispensable for the prevention of $\mathrm{OP}$ and for decreasing the incidence of osteoporotic fractures. Basic measurements are not only suitable for the primary and secondary prevention of OP, but they can also be used during periods of drug treatment or rehabilitation therapy for OP for the entire population. The main basic measurements for preventing OP are as follows.

\section{Lifestyle adjustment}

Lifestyle and patients' behavior are associated with OP and fractures. Tai Ji Quan or square dancing are popular among the Chinese people. Patients should generally avoid cigarette smoking, and the excessive consumption of alcohol and caffeine. ${ }^{113,114}$ Moreover, tea is very popular with Chinese people, and previous studies have demonstrated that tea consumption is a protective factor in maintaining BMD. ${ }^{124}$ However, the relationship between tea intake and the risk of OP and fracture is inconsistent. ${ }^{125-127}$ A sedentary lifestyle or inactivity, which accelerate bone loss, should be avoided among elderly people as much as possible.

\section{Nutrition counseling}

To maintain bone health, adults should maintain a balanced diet that is rich in calcium, has adequate vitamin $\mathrm{D}$, low salt, and appropriate amounts of protein. The Chinese Society of Nutrition recommends that $800 \mathrm{mg}$ per day of calcium for adults is beneficial for obtaining peak bone mass in young people, and at least $1,000 \mathrm{mg}$ per day for postmenopausal women and the older population. ${ }^{38}$ Moreover, vitamin D is essential for the absorption of calcium, and there is increasing recognition of its critical role in bone health, so the supplementing of calcium must be coupled with vitamin D. Adequate exposure to sunlight is beneficial for the synthesis of vitamin D through the skin. A daily intake of 600-800 IU should be recommended for the older population and $800-1,200$ IU for OP patients, ${ }^{38}$ which is in accordance with the National Osteoporosis Foundation's recommendations. ${ }^{128}$ The International Osteoporosis Foundation suggests that the level of 25(OH)D should not be below $30 \mathrm{ng} / \mathrm{mL}(75 \mathrm{nmol} / \mathrm{L})$ in order to decrease the risk of falls and fractures.

Central obesity is a negative factor for bone metabolism. An inverse relationship has been found between the ratio of visceral adipose tissue/subcutaneous adipose tissue and BMD, which might be the result of obesity-induced chronic inflammation. However, weight reduction might not have a negative effect on bone metabolism when there is adequate calcium intake. ${ }^{129,130}$

\section{Physical exercise}

Exercise plays an important role in the management of osteoporotic patients and can result in a myriad of positive benefits, such as the achievement of peak bone mass, a reduction in the risk of $\mathrm{OP}$, and the building or maintenance of bone strength. ${ }^{131}$ Weight-bearing, muscle-strengthening, and balance-training exercises are particularly helpful for improving agility, strength, posture, coordination, and balance, thus reducing the risk of a fall. Recommended activities include walking, jogging, aerobics, stair climbing, field or racquet sports, dancing, and Tai Ji Quan, a traditional Chinese martial art. ${ }^{79}$ However, the severity and progression of the patient's bone loss, as well as the location of any previous fractures, should be taken into account. Hence, OP patients should avoid flexion-biased exercises such as abdominal crunches, lifting heavy weights, and excessive twisting or bending. ${ }^{132}$ 


\section{Reducing fall risk}

Falling plays a critical role in most osteoporotic fractures, and fall prevention is important for patients with OP. ${ }^{133}$ Fall prevention strategies involve checking and correcting vision problems related to age as quickly as possible, evaluating neuromuscular coordination and cognitive function, improving proprioceptive and vestibular systems, reviewing adverse effects of medications (dizziness, hypoglycemia, orthostatic hypotension) and promoting exercise. ${ }^{134,135}$ Another factor that should be given more attention is environmental modification consisting of minimizing safety hazards in the home (installing grab bars/handrails near toilets, providing adequate lighting, providing appropriate shoes, altering slippery and wet surfaces, and eliminating obstructions). ${ }^{136}$ In addition, some assistive devices, such as properly-fitted canes and walkers, and certain types of joint protectors are also useful to facilitate a steadier gait and reduce the risk of a fall. ${ }^{137}$

\section{Reasonable application of glucocorticoid and bone loss prevention}

By using the equivalent of prednisone $5 \mathrm{mg} /$ day for 3-6 months, BMD has been shown to decrease rapidly, and the risk of fracture has increased dramatically (relative ratio $[R R]$ value: any fracture, 1.33 1.91; hip fracture, 1.61 2.01; vertebral fracture, 2.60 2.86; and forearm fracture, 1.09 1.13). Fractures induced by glucocorticoids have three characteristics: ${ }^{138,139}$ first, the risk of fracture has nothing to do with age, sex, and basic diseases; second, hip or rib fracture can still occur even with the normal BMD, therefore, there seems to be no safe dose of glucocorticoid to avoid bone loss and fractures; and third, muscle weakness and myopathy can reduce the ability to balance, which leads to falling and fracturing easily.

The guidelines for the diagnosis and treatment of glucocorticoid-induced OP (GIOP) in the People's Republic of China point out that patients who require the long-term use of glucocorticoids should be measured for BMD every 6-12 months. ${ }^{140}$ Glucocorticoid treatment is defined as less than 3 months for the short term, 3 6 months for the shortto-medium term, and more than 6 months for the long term. ${ }^{141}$ The American College of Rheumatology recommended that patients treated with glucocorticoids (the equivalent dose to prednisone $>5 \mathrm{mg} /$ day) for more than 3 months should take the following treatment measures: ${ }^{142}$ first, they should make improvements to their lifestyle (no smoking and drinking less); second, they should engage in appropriate weight-bearing exercise; third, they should take supplements of calcium and vitamin $\mathrm{D}$; and fourth, they should take bisphosphonates (however, premenopausal women should be careful). If patients require the long-term use of glucocorticoids, and there is an already existing risk for developing OP, preventive measures should be taken more imminently. Apart from improving lifestyle, engaging in appropriate weightbearing exercise, and supplementing calcium and vitamin D, hormone replacement therapy (HRT) should be adopted in a timely way (when there is gonadal dysfunction or other clinical indications), and lumbar spine or hip BMD should be measured regularly. ${ }^{138}$ When the BMD T-score is $<-1$, bisphosphonates should be given, and if the patients are contraindicated for or intolerant to bisphosphonates, we recommended teriparatide or denosumab as an alternative choice, but considering the price and convenience of the two drugs in the People's Republic of China, calcitonin becomes the second choice for most patients. If the BMD is normal, patients should be followed up every 1 2 years, coupled with a measurement of BMD. ${ }^{143}$

At present, agreement has not yet been reached in every country with respect to the prevention and treatment of GIOP, but all the guidelines point out that steps should be taken to measure BMD where there is long-term use of glucocorticoids. ${ }^{144-146}$ Most opinions suggest that bisphosphonates should be taken as the first-line treatment with supplements of calcium and vitamin $\mathrm{D}$, which are the basic drugs for primary and secondary prevention. In 2010, the American College of Rheumatology updated its guidelines for the prevention and treatment of GIOP, focusing on the following points: ${ }^{142}$ first, when planning to use a glucocorticoid, measurements should be taken to prevent and treat GIOP, especially the timely supplementation of calcium and vitamin D; second, bisphosphonates, such as zoledronic acid, are the first choice of treatment; and third, common vitamin $\mathrm{D}$ is useful for decreasing the bone loss induced by low and medium doses of glucocorticoid, but it has no protective effect on OP induced by a high dose of glucocorticoid.

There are five aspects to the prevention of GIOP, which are set out as follows: ${ }^{138,143,147}$ first, avoid the abuse of glucocorticoids as much as possible, and nonglucocorticoid medication should be taken as the first choice by patients. Second, choose the best dosage, usage, and course of treatment. Patients who are used to glucocorticoids should take topical remedies as much as possible in order to reduce the dosage and side effects of glucocorticoids. In addition, oral treatment should be taken as an alternative day therapy, so as to keep the feedback function of the hypothalamic-pituitary-adrenal axis. Third, treatment with the agents should be reduced, or even terminated, as soon as the disease is controlled, and 
if patients need the long-term use of glucocorticoids, the lowest effective dose is recommended. In the past, a daily dose of $7.5 \mathrm{mg}$ of prednisone (5 $\mathrm{mg}$ in the morning, $2.5 \mathrm{mg}$ in the afternoon) was regarded as the "physiological" requirement, but many of these patients have also suffered from GIOP. ${ }^{148}$ Multifactorial analysis has shown that 24-hour urinary cortisol/creatinine excretion is a good index to judge whether the cortisol is excessive or not, and it is a predictor of BMD. Fourth, a combination using antiosteoporotic drugs (for example, using bisphosphonates first, and then activated vitamin D or sex hormones) should be used to prevent GIOP. Last, BMD should be measured regularly.

\section{Suggestions for solving the problems faced by the People's Republic of China concerning OP}

In order to solve the problems that exist in the People's Republic of China about OP, we proposed a number of suggestions, as follows: first, continue to increase the basis for and clinical study investment of preventing OP and improve the quality of research pertaining to the epidemiology of OP by governmental and nongovernmental methods. Second, strengthen the professional teaching of OP, have doctors engage in OP education as on-the-job continuing education training content (so as to improve the understanding of OP), and encourage medical staff to pay more attention to OP. Third, improve the ability to diagnose and treat OP by setting up specialized OP outpatient services, and offer different equipment (DEXA or ultrasonic instruments) according to different levels of hospitals and economic situations; if this is done, patients with back pain or osteoporotic fractures can be diagnosed and treated earlier. Fourth, enhance popular science education and improve the awareness of OP among people, especially those at high risk for OP. Most importantly, establish a healthy lifestyle of drinking more milk, engaging in more exercise, and increasing sun exposure, which is the key to increasing adolescent peak bone mass and maintaining young bone health. ${ }^{18}$ Therefore, everyone should understand that no one is immune to OP, and that it is a silent disease that is present before a fragility fracture occurs, which people can do much to prevent.

\section{Pharmacologic treatment}

The guidelines for the prevention and treatment of OP proposed by the Chinese Society of Osteoporosis and Bone Mineral Research (CSOBMR) in the People's Republic of China ${ }^{38}$ recommends pharmacological treatment for the following indications: 1) postmenopausal women and men aged 50 years or older (they should be considered for treatment if they have a hip or vertebral fracture, including a fragility fracture);
2) a Dual Energy X-ray Absorptiometry (DEXA) T-score below -2.5 at the femoral neck or spine after excluding other secondary causes; 3) an osteopenic patient with a T-score of -1.0 to -2.5 , and with at least one risk factor for OP with or without fracture; and 4) an Osteoporosis Self-assessment Tool for Asians (OSAT) screening for high risk and a 10-year probability of a major osteoporotic fracture of at least $20 \%$, or a hip fracture risk of at least 3\% (based on FRAX).

The drugs approved by the State Food and Drug Administration for the treatment and prevention of OP can be classified into two categories: antiresorptive agents and anabolic agents. Antiresorptive agents include bisphosphonates, calcitonin, HRT, selective estrogen receptor modulators, and denosumab. Anabolic agents consist of teriparatide and intact parathyroid hormone (PTH), while another mixed bone-forming and antiresorptive drug is strontium ranelate. Their specific effects on the prevention and treatment of OP are shown in Table 3. Besides, Chinese herbal medicine is a popular alternative treatment in the People's Republic of China. The goal of all treatment is to build bone and reduce the risk of fracture.

\section{Traditional Chinese medicine}

In the People's Republic of China, people are looking for complementary or alternative medicines to treat OP. Traditional Chinese medicines have been used to treat bone-related diseases for thousands of years in the People's Republic of China. ${ }^{149,150}$ A study of their mechanisms has shown that some Chinese herbal medicines have an estrogen-like effect, which was considered to be due to phytoestrogens, ${ }^{151}$ and they may induce osteoblast differentiation and osteogenesis. ${ }^{152}$ It has been demonstrated that some Chinese herbal medicines have therapeutic anti-OP effects in animal models ${ }^{153,154}$ or in postmenopausal women. ${ }^{155}$ However, due to the lack of large multicenter samples and rigorous control studies to identify the anti-OP effect of Chinese herbal medicines, they have only been recommended as alternative or supplementary medications for OP treatment at the present stage. It is well known that there are plenty of natural resources with an osteogenesis effect, either in the form of medicinal herbs or bioactive components. Further work should therefore be done to investigate their mechanisms and adverse effects by means of clinical investigations in a strict multicenter, randomized control study before their clinical use.

\section{Combination therapies}

The combined application of antiosteoporotic drugs is more complex, bearing in mind the interaction between drugs. By combining bisphosphonates and HRT, BMD increased 


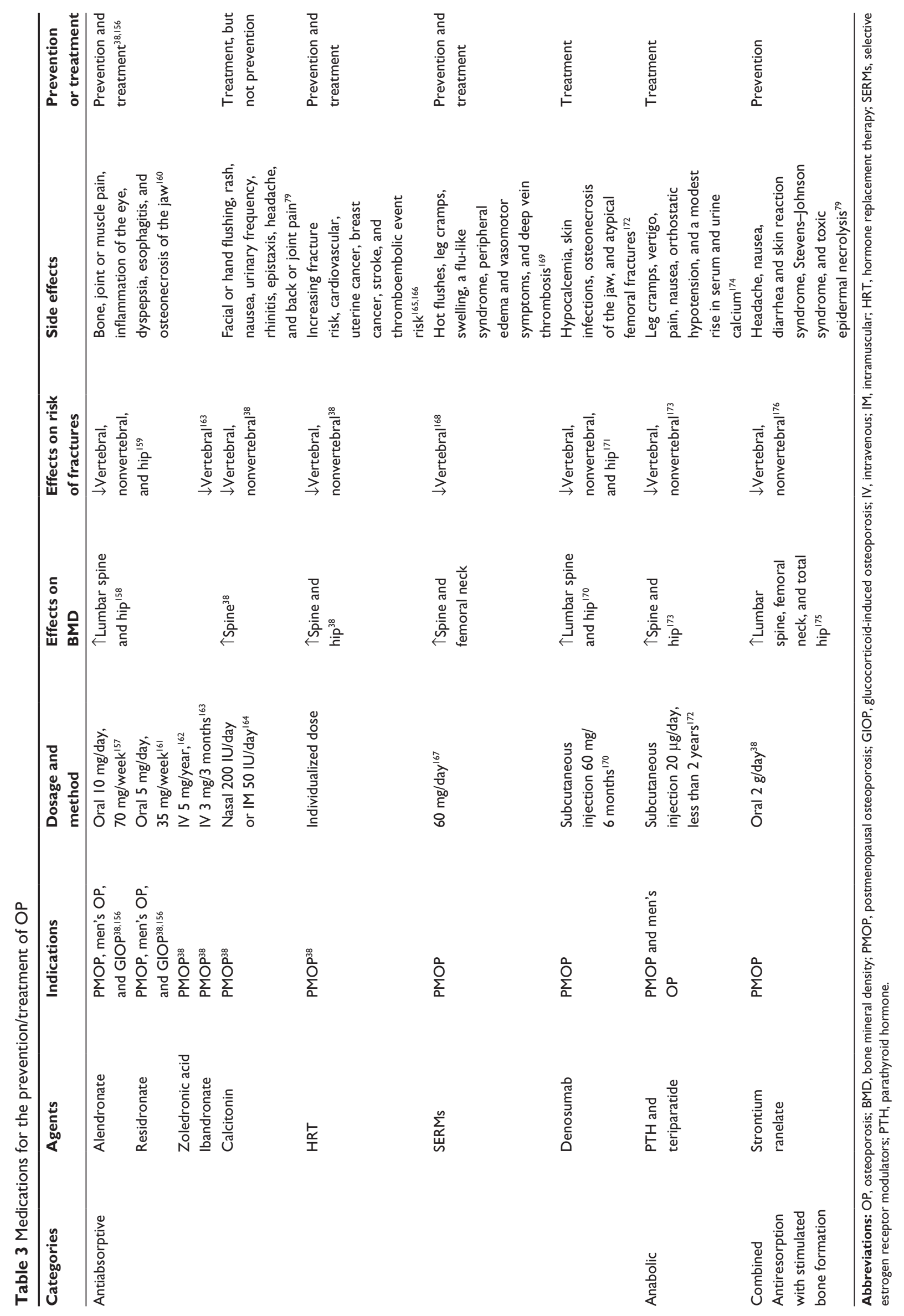


more in the lumbar spine and hip when compared with either agent alone. ${ }^{177}$ But several noted studies showed that the concurrent use of bisphosphonates and PTH attenuated the anabolic effects of PTH on BMD, rather than obtaining addictive effects in vivo and in vitro. ${ }^{178-180}$ However, starting the drugs sequentially rather than simultaneously that is to say, treatment with PTH several months before adding bisphosphonates - was associated with a greater and more rapid increase in BMD at the lumbar spine and hip. ${ }^{181}$ Nevertheless, the combination of denosumab and teriparatide improved BMD at the spine and hip more than with either denosumab or teriparatide alone in patients with severe OP. ${ }^{182,183}$ Further research is still needed to determine whether these combinations result in improved fracture protection, and their long-term safety implications should be considered.

\section{Future prospects}

With an increase in life expectancy and the aging of the population in the People's Republic of China, the number of people with OP will increase greatly in future generations. This is coupled with a mounting number of osteoporotic fractures, which will have a far-reaching and devastating impact on the individuals themselves, and also on the health service, economy, and population as a whole because of the high rates of morbidity and mortality, and the heavy economic burden. Fortunately, many of the risk factors for this disease are well recognized, and models for predicting the probability of OP are currently being developed, making OP preventable. Moreover, measurements should be taken to prevent OP and enable therapy for OP to be provided. Other than the common drugs mentioned earlier, there are also some other osteoporotic drugs, such as novel selective estrogen receptor modulators (bazedoxifene), ${ }^{184}$ antisclerostin antibodies (sclerostin), ${ }^{185}$ cathepsin K inhibitors (odanacatib), ${ }^{186}$ and stem cell therapy, ${ }^{187}$ which act more directly on bone-forming pathways to enhance bone formation without provoking an osteoclast-mediated bone-resorptive response. It will take several years for these to be applied in clinical practice, however, before Phase III trials are finished. In fact, weighing the data on side effects, the cost of the drugs, the effects compared with the already available drugs, the risk rate of osteoporotic fractures, and the patients' perspectives are critical when making decisions about the treatment of OP. Of course, nonpharmacological interventions (adequate calcium and vitamin D supply, regular exercise, the prevention of falls, smoking cessation, limited alcohol intake, etc) are also important. Therefore, a good understanding of the epidemiology of OP and osteoporotic fractures can help identify those at greatest risk and permit the appropriate targeting of treatment for the prevention of fractures. As with other chronic diseases, each patient should make a lifelong plan for OP prevention and treatment.

\section{Acknowledgments}

This work was supported by funding from the National Natural Science Foundation of China (grant number 81270962), the National Basic Research Program of China (973 Program) (2014CB942903), the Program for New Century Excellent Talents in University (NCET-13-0601), and the Fundamental Research Funds for the Central Universities of Central South University (Grant NO. 2015zzts313).

\section{Disclosure}

The authors report no conflicts of interest in this work.

\section{References}

1. Consensus development conference: diagnosis, prophylaxis, and treatment of osteoporosis. Am J Med. 1993;94(6):646-650.

2. O'Neill TW, Felsenberg D, Varlow J, Cooper C, Kanis JA, Silman AJ. The prevalence of vertebral deformity in European men and women: the European Vertebral Osteoporosis Study. J Bone Miner Res. 1996; 11(7):1010-1018.

3. Looker AC, Orwoll ES, Johnston CC Jr, et al. Prevalence of low femoral bone density in older U.S. adults from NHANES III. J Bone Miner Res. 1997;12(11):1761-1768.

4. Kanis JA, Johnell O, Oden A, Jonsson B, De Laet C, Dawson A. Risk of hip fracture according to the World Health Organization criteria for osteopenia and osteoporosis. Bone. 2000;27(5):585-590.

5. Ministry of Civil Affairs released 2013 Social Services Development Statistics Bulletin [webpage on the Internet]. Ministry of Civil Affairs of the People's Republic of China. Available from http://www.mca. gov.cn/article/zwgk/mzyw/201406/20140600654488.shtml. Accessed May 21, 2015.

6. Guillemin F, Martinez L, Calvert M, et al. Fear of falling, fracture history, and comorbidities are associated with health-related quality of life among European and US women with osteoporosis in a large international study. Osteoporos Int. 2013;24(12):3001-3010.

7. Harvey NC, Matthews P, Collins R, Cooper C; UK Biobank Musculoskeletal Advisory Group. Osteoporosis epidemiology in UK Biobank: a unique opportunity for international researchers. Osteoporos Int. 2013; 24(12):2903-2905

8. Fontenot HB and Harris AL, Pharmacologic management of osteoporosis. J Obstet Gynecol Neonatal Nurs. 2014;43(2):236-245.

9. Levine JP Pharmacologic and nonpharmacologic management of osteoporosis. Clin Cornerstone. 2006;8(1)40-53.

10. Assessment of fracture risk and its application to screening for postmenopausal osteoporosis. Report of a WHO Study Group. World Health Organ Tech Rep Ser. 1994;843:1-129.

11. Kung AW, Fan T, Xu L, et al. Factors influencing diagnosis and treatment of osteoporosis after a fragility fracture among postmenopausal women in Asian countries: a retrospective study. BMC Womens Health. 2013; 13:7.

12. Kanis JA, Delmas P, Burckhardt P, Cooper C, Torgerson D. Guidelines for diagnosis and management of osteoporosis. The European Foundation for Osteoporosis and Bone Disease. Osteoporos Int. 1997;7(4): 390-406. 
13. Kanis JA, Glüer CC. An update on the diagnosis and assessment of osteoporosis with densitometry. Committee of Scientific Advisors, International Osteoporosis Foundation. Osteoporos Int. 2000;11(3):192-202.

14. Kanis JA, Melton LJ 3rd, Christiansen C, Johnston CC, Khaltaev N. The diagnosis of osteoporosis. J Bone Miner Res. 1994;9(8):1137-1141.

15. Yang Y, Wang B, Fei Q, et al. Validation of an osteoporosis selfassessment tool to identify primary osteoporosis and new osteoporotic vertebral fractures in postmenopausal Chinese women in Beijing. BMC Musculoskelet Disord. 2013;14:271.

16. Geohive [homepage on the Internet]. Global Population Statistics. Available from www.geohive.com. Accessed 21 May, 2015.

17. National Bureau of Statistics of the People's Republic of China [homepage on the Internet]. China Statistical Yearbook. Available from http:// www.stats.gov.cn/tjsj/ndsj/. Accessed 21 May, 2015.

18. Qingyun Xuan, et al. Interpretation for the "White paper of Osteoporosis prevention in China" in the twelfth orthopaedic academic conference of Chinese Medical Association and the fifth COA International Academic Conference, 2010. Chengdu. Sichuan province of China. Chinese.

19. Liu ZH, Zhao YL, Ding GZ, Zhou Y. Epidemiology of primary osteoporosis in China. Osteoporos Int. 1997;7 Suppl 3:S84-S87.

20. Li N, Ou P, Zhu H, Yang D, Zheng P. Prevalence rate of osteoporosis in the mid - aged and elderly in selected parts of China. Chin Med J (Engl). 2002;115(5):773-775.

21. Zhang Z, Shen X, Zhang H, et al. The relationship between body composition and fracture risk using the FRAX model in central south Chinese postmenopausal women. Clin Endocrinol (Oxf). 2012;77(4):524-530.

22. Löfman O, Berglund K, Larsson L, Toss G. Changes in hip fracture epidemiology: redistribution between ages, genders and fracture types Osteoporos Int. 2002;13(1):18-25.

23. Wang J, Wang Y, Liu WD, Wang F, Yin ZS. Hip fractures in Hefei, China: the Hefei osteoporosis project. $J$ Bone Miner Metab. 2014;32(2):206-214.

24. Dhanwal DK, Cooper C, Dennison EM. Geographic variation in osteoporotic hip fracture incidence: the growing importance of Asian influences in coming decades. J Osteoporos. 2010;2010:757102.

25. El Maghraoui A, Ngbanda AR, Bensaoud N, Bensaoud M, Rezqi A, Tazi MA.Age-adjusted incidence rates of hip fractures between 2006 and 2009 in Rabat, Morocco. Osteoporos Int. 2013;24(4):1267-1273.

26. Doheny MO, Sedlak CA, Estok PJ, Zeller R. Osteoporosis knowledge, health beliefs, and DXA T-scores in men and women 50 years of age and older. Orthop Nurs. 2007;26(4):243-250.

27. Juby AG, Davis P. A prospective evaluation of the awareness, knowledge, risk factors and current treatment of osteoporosis in a cohort of elderly subjects. Osteoporos Int. 2001;12(8):617-622.

28. Wong CP, Lok MK, Wun YT, Pang SM. Chinese men's knowledge and risk factors of osteoporosis: compared with women's. Am J Mens Health. 2014;8(2):159-166

29. Lee LY, Lai EK. Osteoporosis in older Chinese men: knowledge and health beliefs. J Clin Nurs. 2006;15(3):353-355.

30. Center JR, Nguyen TV, Schneider D, Sambrook PN, Eisman JA. Mortality after all major types of osteoporotic fracture in men and women: an observational study. Lancet. 1999;353(9156):878-882.

31. Bliuc D, Nguyen ND, Milch VE, Nguyen TV, Eisman JA, Center JR. Mortality risk associated with low-trauma osteoporotic fracture and subsequent fracture in men and women. JAMA. 2009;301(5):513-521.

32. Wu XP, Hou YL, Zhang H, et al. Establishment of BMD reference databases for the diagnosis and evaluation of osteoporosis in central southern Chinese men. J Bone Miner Metab. 2008;26(6):586-594.

33. Donaldson MG, Cawthon PM, Lui LY, et al; Osteoporotic Fractures in Men (MrOS) Study Group. Estimates of the proportion of older white men who would be recommended for pharmacologic treatment by the new US National Osteoporosis Foundation guidelines. J Bone Miner Res. 2010;25(7):1506-1511.

34. Gourlay ML, Fine JP, Preisser JS, et al; Study of Osteoporotic Fractures Research Group. Bone-density testing interval and transition to osteoporosis in older women. N Engl J Med. 2012;366(3):225-233.
35. Guo P, Wang S, Zhu Y, et al. Prevalence of osteopenia and osteoporosis and factors associated with decreased bone mineral density in elderly inpatients with psychiatric disorders in Huzhou, China. Shanghai Arch Psychiatry. 2012;24(5):262-270.

36. Melton LJ 3rd, Thamer M, Ray NF, et al. Fractures attributable to osteoporosis: report from the National Osteoporosis Foundation. J Bone Miner Res. 1997;12(1):16-23.

37. Johnell O, Kanis JA. An estimate of the worldwide prevalence and disability associated with osteoporotic fractures. Osteoporos Int. 2006; 17(12):1726-1733.

38. China Medical Association of Osteoporosis and Bone Mineral Research. Guidelines for diagnosis and treatment of primary osteoporsis (2011). Chinese Journal of Osteoporosis and Bone Mineral Research. 2011; 4(1):2-17. Chinese.

39. Liu JM, Ma LY, Bi YF, et al. A population-based study examining calcaneus quantitative ultrasound and its optimal cut-points to discriminate osteoporotic fractures among 9352 Chinese women and men. J Clin Endocrinol Metab. 2012;97(3):800-809.

40. Huo D, Li L. [A case - control study on risk factors for hip fracture in the middle - aged and elderly in Beijing]. Zhonghua Liu Xing Bing Xue Za Zhi. 2000;21(1):37-40. Chinese.

41. Jiang BQ, Zhong PH, Cheng XB, Yang XL, Yang J, Cao YF. Investigation of health and nutrition status of middle-aged and old residents in the urban district of Chongqing. Asia Pac J Clin Nutr. 2007;16 Suppl 1:17-21.

42. Cheung EY, Ho AY, Lam KF, Tam S, Kung AW. Determinants of bone mineral density in Chinese men. Osteoporos Int. 2005;16(12): 1481-1486.

43. Lau EM, Leung PC, Kwok T, et al. The determinants of bone mineral density in Chinese men - results from Mr Os (Hong Kong), the first cohort study on osteoporosis in Asian men. Osteoporos Int. 2006;17(2): 297-303.

44. Marshall D, Johnell O, Wedel H. Meta-analysis of how well measures of bone mineral density predict occurrence of osteoporotic fractures. BMJ. 1996;312(7041):1254-1259.

45. Stone KL, Seeley DG, Lui LY, et al; Osteoporotic Fractures Research Group. BMD at multiple sites and risk of fracture of multiple types: long-term results from the Study of Osteoporotic Fractures. J Bone Miner Res. 2003;18(11):1947-1954.

46. Kanis JA, Johnell O, Oden A, Johansson H, McCloskey E. FRAX and the assessment of fracture probability in men and women from the UK. Osteoporos Int. 2008;19(4):385-397.

47. Tsang SW, Kung AW, Kanis JA, Johansson H, Oden A. Ten-year fracture probability in Hong Kong Southern Chinese according to age and BMD femoral neck T-scores. Osteoporos Int. 2009;20(11):1939-1945.

48. Zhang Z, Ou Y, Sheng Z, Liao E. How to decide intervention thresholds based on FRAX in central south Chinese postmenopausal women. Endocrine. 2014;45(2):195-197.

49. Peifang W, et al. The cost statistic of osteoporotic fracture treatment from 2000 to 2004. Chinese Journal of Osteoporosis. 2006;(03):274277. Chinese.

50. Luo LZ, Xu L. [Study on direct economic-burden and its risk factors of osteoporotic hip fracture]. Zhonghua Liu Xing Bing Xue Za Zhi. 2005;26(9):669-672. Chinese.

51. Qu B, Ma Y, Yan M, et al. The economic burden of fracture patients with osteoporosis in western China. Osteoporos Int. 2014;25(7): 1853-1860.

52. Gullberg B, Johnell O, Kanis JA. World-wide projections for hip fracture. Osteoporos Int. 1997;7(5):407-413.

53. Cooper C, Cole ZA, Holroyd CR, et al; IOF CSA Working Group on Fracture Epidemiology. Secular trends in the incidence of hip and other osteoporotic fractures. Osteoporos Int. 2011;22(5):1277-1288.

54. Cummings SR, Xu L, Chen X, Zhao X, Yu W, Ge Q. Bone mass, rates of osteoporotic fractures, and prevention of fractures: are there differences between China and Western countries? Chin Med Sci J. 1994;9(3): 197-200.

55. Xu L, Lu A, Zhao X, Chen X, Cummings SR. Very low rates of hip fracture in Beijing, People's Republic of China the Beijing Osteoporosis Project. Am J Epidemiol. 1996;144(9):901-907. 
56. Yan L, Zhou B, Prentice A, Wang X, Golden MH. Epidemiological study of hip fracture in Shenyang, People's Republic of China. Bone. 1999;24(2):151-155.

57. Zhang L, Cheng A, Bai Z, et al. Epidemiology of cervical and trochanteric fractures of the proximal femur in 1994 in Tangshan, China. J Bone Miner Metab. 2000;18(2):84-88.

58. Tian FM, Zhang L, Zhao HY, Liang CY, Zhang N, Song HP. An increase in the incidence of hip fractures in Tangshan, China. Osteoporos Int. 2014;25(4):1321-1325.

59. Xia WB, He SL, Xu L, et al. Rapidly increasing rates of hip fracture in Beijing, China. J Bone Miner Res. 2012;27(1):125-129.

60. Wang CB, Lin CF, Liang WM, et al. Excess mortality after hip fracture among the elderly in Taiwan: a nationwide population-based cohort study. Bone. 2013;56(1):147-153.

61. Hahn BH. Osteoporosis: diagnosis and management. Bull Rheum Dis. 1988;38(2):1-9.

62. Chau PH, Wong M, Lee A, Ling M, Woo J. Trends in hip fracture incidence and mortality in Chinese population from Hong Kong 2001-2009. Age Ageing. 2013;42(2):229-233.

63. Brauer CA, Coca-Perraillon M, Cutler DM, Rosen AB. Incidence and mortality of hip fractures in the United States. JAMA. 2009;302(14): 1573-1579

64. Haentjens P, Autier P, Barette M, Venken K, Vanderschueren D, Boonen S; Hip Fracture Study Group. Survival and functional outcome according to hip fracture type: a one-year prospective cohort study in elderly women with an intertrochanteric or femoral neck fracture. Bone. 2007;41(6):958-964.

65. Shyu YI, Chen MC, Liang J, Lu JF, Wu CC, Su JY. Changes in quality of life among elderly patients with hip fracture in Taiwan. Osteoporos Int. 2004;15(2):95-102.

66. Ström O, Borgstrom F, Zethraeus N, et al. Long-term cost and effect on quality of life of osteoporosis-related fractures in Sweden. Acta Orthop. 2008;79(2):269-280.

67. Ekman EF. The role of the orthopaedic surgeon in minimizing mortality and morbidity associated with fragility fractures. $J$ Am Acad Orthop Surg. 2010;18(5):278-285.

68. Jiang HX, Majumdar SR, Dick DA, et al. Development and initial validation of a risk score for predicting in-hospital and 1-year mortality in patients with hip fractures. J Bone Miner Res. 2005;20(3):494-500.

69. Baudoin C, Fardellone P, Bean K, Ostertag-Ezembe A, Hervy F. Clinical outcomes and mortality after hip fracture: a 2-year follow-up study. Bone. 1996;18(3 Suppl):149S-157S.

70. Cummings SR, Melton LJ. Epidemiology and outcomes of osteoporotic fractures. Lancet. 2002;359(9319):1761-1767.

71. Suzuki N, Ogikubo O, Hansson T. The course of the acute vertebral body fragility fracture: its effect on pain, disability and quality of life during 12 months. Eur Spine J. 2008;17(10):1380-1390.

72. Kung AW. Epidemiology and diagnostic approaches to vertebral fractures in Asia. J Bone Miner Metab. 2004;22(3):170-175.

73. Suzuki N, Ogikubo O, Hansson T. The prognosis for pain, disability, activities of daily living and quality of life after an acute osteoporotic vertebral body fracture: its relation to fracture level, type of fracture and grade of fracture deformation. Eur Spine J. 2009;18(1): $77-88$.

74. Graziotti PJ, Graziotti CR, Sangster AM. Significance of preoperative MRI in establishing levels of augmentation for percutaneous vertebroplasty. J Pain Res. 2013;6:359-365.

75. Ling X, Cummings SR, Mingwei Q, et al. Vertebral fractures in Beijing, China: the Beijing Osteoporosis Project. J Bone Miner Res. 2000; 15(10):2019-2025.

76. Kwok AW, Gong JS, Wang YX, et al. Prevalence and risk factors of radiographic vertebral fractures in elderly Chinese men and women: results of Mr OS (Hong Kong) and Ms OS (Hong Kong) studies. Osteoporos Int. 2013;24(3):877-885.

77. Tsai K, Twu S, Chieng P, Yang R, Lee T. Prevalence of vertebral fractures in Chinese men and women in urban Taiwanese communities. Calcif Tissue Int. 1996;59(4):249-253.
78. Tsang SW, Bow CH, Chu EY, Yeung SC, Soong CC, Kung AW. Clinical risk factor assessment had better discriminative ability than bone mineral density in identifying subjects with vertebral fracture. Osteoporos Int. 2011;22(2):667-674.

79. Ip I, Cheung SK, Cheung TC, et al; OSHK Task Group for Formulation of 2013 OSHK Guideline for Clinical Management of Postmenopausal Osteoporosis in Hong Kong; Osteoporosis Society of Hong Kong. The Osteoporosis Society of Hong Kong (OSHK): 2013 OSHK guideline for clinical management of postmenopausal osteoporosis in Hong Kong. Hong Kong Med J. 2013;19 Suppl 2:1-40.

80. Truumees E. Osteoporosis. Spine (Phila Pa 1976). 2001;26(8): 930-932.

81. Borgström F, Zethraeus N, Johnell O, et al. Costs and quality of life associated with osteoporosis-related fractures in Sweden. Osteoporos Int. 2006;17(5):637-650.

82. Lindsay R, Silverman SL, Cooper C, et al. Risk of new vertebral fracture in the year following a fracture. JAMA. 2001;285(3):320-323.

83. Hasserius R, Karlsson MK, Nilsson BE, Redlund-Johnell I, Johnell O; European Vertebral Osteoporosis Study. Prevalent vertebral deformities predict increased mortality and increased fracture rate in both men and women: a 10-year population-based study of 598 individuals from the Swedish cohort in the European Vertebral Osteoporosis Study. Osteoporos Int. 2003;14(1):61-68.

84. Cooper C, Melton LJ 3rd. Epidemiology of osteoporosis. Trends Endocrinol Metab. 1992;3(6):224-229.

85. Dias JJ. An analysis of the nature of injury in fractures of the neck of the femur. Age Ageing. 1987;16(6):373-377.

86. Jacobsen SJ, Sargent DJ, Atkinson EJ, O'Fallon WM, Melton LJ. Contribution of weather to the seasonality of distal forearm fractures: a population-based study in Rochester, Minnesota. Osteoporos Int. 1999; 9(3):254-259.

87. Edwards BJ, Song J, Dunlop DD, Fink HA, Cauley JA. Functional decline after incident wrist fractures - Study of Osteoporotic Fractures: prospective cohort study. BMJ. 2010;341:c3324.

88. Pike C, Birnbaum HG, Schiller M, Sharma H, Burge R, Edgell ET. Direct and indirect costs of non-vertebral fracture patients with osteoporosis in the US. Pharmacoeconomics. 2010;28(5):395-409.

89. Häussler B, Gothe H, Göl D, Glaeske G, Pientka L, Felsenberg D. Epidemiology, treatment and costs of osteoporosis in Germany - the BoneEVA Study. Osteoporos Int. 2007;18(1):77-84.

90. Reid IR. Relationships between fat and bone. Osteoporos Int. 2008; 19(5):595-606.

91. Liu S, Li J, Sheng Z, Wu X and Liao E. Relationship between body composition and age, menopause and its effects on bone mineral density at segmental regions in Central Southern Chinese postmenopausal elderly women with and without osteoporosis. Arch Gerontol Geriatr. 2011.53(2):192-197.

92. Hsu YH, Venners SA, Terwedow HA, Feng Y, Niu T et al. Relation of body composition, fat mass, and serum lipids to osteoporotic fractures and bone mineral density in Chinese men and women. Am J Clin Nutr. 2006;83(1):146-154.

93. Shan PF, Wu XP, Zhang H, Cao XZ, Yuan LQ, Liao EY. Age-related bone mineral density, osteoporosis rate and risk of vertebral fracture in mainland Chinese women with type 2 diabetes mellitus. $J$ Endocrinol Invest. 2011;34(3):190-196.

94. Zhou Y, Li Y, Zhang D, Wang J, Yang H. Prevalence and predictors of osteopenia and osteoporosis in postmenopausal Chinese women with type 2 diabetes. Diabetes Res Clin Pract. 2010;90(3):261-269.

95. Hannan MT, Felson DT, Dawson-Hughes B, et al. Risk factors for longitudinal bone loss in elderly men and women: the Framingham Osteoporosis Study. J Bone Miner Res. 2000;15(4):710-720.

96. Sheng Z, Xu K, Ou Y, et al. Relationship of body composition with prevalence of osteoporosis in central south Chinese postmenopausal women. Clin Endocrinol (Oxf). 2011;74(3):319-324.

97. Blum M, Harris SS, Must A, et al. Leptin, body composition and bone mineral density in premenopausal women. Calcif Tissue Int. 2003; 73(1):27-32. 
98. Morita Y, Iwamoto I, Mizuma N, et al. Precedence of the shift of bodyfat distribution over the change in body composition after menopause. J Obstet Gynaecol Res. 2006;32(5):513-516.

99. Kang DH, Guo LF, Guo T, et al. Association of body composition with bone mineral density in northern Chinese men by different criteria for obesity. J Endocrinol Invest. Epub 2014 Sep 25.

100. Norman AW, Bouillon R, Whiting SJ, Vieth R, Lips P. 13th Workshop consensus for vitamin D nutritional guidelines. J Steroid Biochem Mol Biol. 2007;103(3-5):204-205.

101. Foo LH, Zhang Q, Zhu K, et al. Relationship between vitamin D status, body composition and physical exercise of adolescent girls in Beijing. Osteoporos Int. 2009;20(3):417-425.

102. Lu L, Yu Z, Pan A, et al. Plasma 25-hydroxyvitamin D concentration and metabolic syndrome among middle-aged and elderly Chinese individuals. Diabetes Care. 2009;32(7):1278-1283.

103. Yan L, Prentice A, Zhang H, Wang X, Stirling DM, Golden MM. Vitamin D status and parathyroid hormone concentrations in Chinese women and men from north-east of the People's Republic of China Eur J Clin Nutr. 2000;54(1):68-72.

104. Zhen D, Liu L, Guan C, Zhao N, Tang X. High prevalence of vitamin D deficiency among middle-aged and elderly individuals in northwestern China: its relationship to osteoporosis and lifestyle factors. Bone. 2015;71:1-6.

105. Wat WZ, Leung JY, Tam S, Kung AW. Prevalence and impact of vitamin D insufficiency in southern Chinese adults. Ann Nutr Metab. 2007;51(1):59-64.

106. Xia ZZ, Xia Z, Wu W, et al. High prevalence of vitamin D insufficiency and deficiency among postmenopausal women in China. The 7th International Conference on Osteoporosis and Bone Metabolism Abstract, 2014.

107. Roy DK, Berry JL, Pye SR, et al. Vitamin D status and bone mass in UK South Asian women. Bone. 2007;40(1):200-204.

108. Kuchuk NO, Pluijm SM, van Schoor NM, Looman CW, Smit JH, Lips P. Relationships of serum 25-hydroxyvitamin D to bone mineral density and serum parathyroid hormone and markers of bone turnover in older persons. J Clin Endocrinol Metab. 2009;94(4):1244-1250.

109. Li S, Ou Y, Zhang H, et al. Vitamin D status and its relationship with body composition, bone mineral density and fracture risk in urban central south Chinese postmenopausal women. Ann Nutr Metab. 2014;64(1):13-19.

110. Woo J, Leung SS, Ho SC, Lam TH, Janus ED. Dietary intake and practices in the Hong Kong Chinese population. J Epidemiol Community Health. 1998;52(10):631-637.

111. Nelson ME, Fiatarone MA, Morganti CM, Trice I, Greenberg RA, Evans WJ. Effects of high-intensity strength training on multiple risk factors for osteoporotic fractures. A randomized controlled trial. JAMA. 1994;272(24):1909-1914.

112. Zhang GS, Peng HL, Deng MY, et al. Mah-Jong-related deep vein thrombosis. Lancet. 2010;375(9733):2214

113. Nelson HD, Nevitt MC, Scott JC, Stone KL, Cummings SR. Smoking, alcohol, and neuromuscular and physical function of older women. Study of Osteoporotic Fractures Research Group. JAMA. 1994; 272(23):1825-1831.

114. Center JR, Bliuc D, Nguyen TV, Eisman JA. Risk of subsequent fracture after low-trauma fracture in men and women. JAMA. 2007;297(4): 387-394.

115. Ioannidis JP, Ng MY, Sham PC, et al. Meta-analysis of genome-wide scans provides evidence for sex- and site-specific regulation of bone mass. J Bone Miner Res. 2007;22(2):173-183.

116. Richards JB, Rivadeneira F, Inouye M, et al. Bone mineral density, osteoporosis, and osteoporotic fractures: a genome-wide association study. Lancet. 2008;371(9623):1505-1512.

117. Styrkarsdottir U, Halldorsson BV, Gretarsdottir S, et al. New sequence variants associated with bone mineral density. Nat Genet. 2009; 41(1):15-17.

118. Liu JM, Zhang MJ, Zhao L, et al. Analysis of recently identified osteoporosis susceptibility genes in Han Chinese women. J Clin Endocrinol Metab. 2010;95(9):E112-E120.
119. Li N, Wang X, Jiang Y, et al. Association of GALNT3 gene polymorphisms with bone mineral density in Chinese postmenopausal women: the Peking Vertebral Fracture study. Menopause. 2014;21(5): 515-521.

120. Cummings SR, Nevitt MC, Browner WS, et al. Risk factors for hip fracture in white women. Study of Osteoporotic Fractures Research Group. N Engl J Med. 1994;332(12):767-773.

121. NIH Consensus Development Panel on Osteoporosis Prevention, Diagnosis, and Therapy. Osteoporosis prevention, diagnosis, and therapy. JAMA. 2001;285(6):785-795.

122. Khosla S, Bilezikian JP. The role of estrogens in men and androgens in women. Endocrinol Metab Clin North Am. 2003;32(1):195-218.

123. Levine JP. Pharmacologic and nonpharmacologic management of osteoporosis. Clin Cornerstone. 2006;8(1):40-53.

124. Wu CH, Yang YC, Yao WJ, Lu FH, Wu JS, Chang CJ. Epidemiological evidence of increased bone mineral density in habitual tea drinkers. Arch Intern Med. 2002;162(9):1001-1006.

125. Keramat A, Patwardhan B, Larijani B, et al. The assessment of osteoporosis risk factors in Iranian women compared with Indian women BMC Musculoskelet Disord. 2008;9:28.

126. Hernández-Avila M, Stampfer MJ, Ravnikar VA, et al. Caffeine and other predictors of bone density among pre- and perimenopausal women. Epidemiology. 1993;4(2):128-134.

127. Hamdi Kara I, Aydin S, Gemalmaz A, et al. Habitual tea drinking and bone mineral density in postmenopausal Turkish women: investigation of prevalence of postmenopausal osteoporosis in Turkey (IPPOT Study). Int J Vitam Nutr Res. 2007;77(6):389-397.

128. Berry SD, Kiel DP, Donaldson MG, et al. Application of the National Osteoporosis Foundation Guidelines to postmenopausal women and men: the Framingham Osteoporosis Study. Osteoporos Int. 2010;21(1): 53-60.

129. Tran HA, Petrovsky N. Pregnancy-associated osteoporosis with hypercalcaemia. Intern Med J. 2002;32(9-10):481-485.

130. Peris P, Guañabens N, Monegal A, et al. Pregnancy associated osteoporosis: the familial effect. Clin Exp Rheumatol. 2002;20(5):697-700.

131. Ernst E. Exercise for female osteoporosis. A systematic review of randomised clinical trials. Sports Med. 1998;25(6):359-368.

132. Bonner FJ, Sinaki M, Grabois M, et al. Health professional's guide to rehabilitation of the patient with osteoporosis. Osteoporos Int. 2003; 14 Suppl 2:S1-S22.

133. Grisso JA, Kelsey JL, Strom BL, et al. Risk factors for falls as a cause of hip fracture in women. The Northeast Hip Fracture Study Group. N Engl J Med. 1991;324(19):1326-1331.

134. Panel on Prevention of Falls in Older Persons, American Geriatrics Society and British Geriatrics Society. Summary of the Updated American Geriatrics Society/British Geriatrics Society clinical practice guideline for prevention of falls in older persons. J Am Geriatr Soc. 2011;59(1):148-157.

135. Management of osteoporosis in postmenopausal women: 2010 position statement of The North American Menopause Society. Menopause. 2010;17(1):25-54; quiz 55-56.

136. Wolf SL, Barnhart HX, Kutner NG, McNeely E, Coogler C, Xu T. Reducing frailty and falls in older persons: an investigation of Tai Chi and computerized balance training. Atlanta FICSIT Group. Frailty and Injuries: Cooperative Studies of Intervention Techniques. J Am Geriatr Soc. 1996;44(5):489-497.

137. Lim MR, Huang RC, Wu A, Girardi FP, Cammisa FP Jr. Evaluation of the elderly patient with an abnormal gait. J Am Acad Orthop Surg. 2007;15(2):107-117.

138. Bachmeyer C, Gauthier M. How to prevent glucocorticoid-induced osteoporosis. Cleve Clin J Med. 2010;77(11):762; author reply 762.

139. Pereira RM, Carvalho JF, Canalis E. Glucocorticoid-induced osteoporosis in rheumatic diseases. Clinics (Sao Paulo). 2010;65(11):1197-1205

140. The Chinese Society of Osteoporosis and Bone Mineral Research. Treatment guideline of glucocorticoid-induced osteoporosis. chin $j$ gen pract. 2006;(08):460-461. Chinese. 
141. Chinese Medical Association of Rheumatology. Experts consensus on diagnosis and treatment of glucocorticoid-induced osteoporosis. Chinese Journal of Rheumatology. 2013;17(6):363-368. Chinese.

142. Grossman JM, Gordon R, Ranganath VK, et al. American College of Rheumatology 2010 recommendations for the prevention and treatment of glucocorticoid-induced osteoporosis. Arthritis Care Res (Hoboken). 2010;62(11):1515-1526.

143. Roux C, Rajzbaum G, Morel G, et al. Management of glucocorticoidinduced osteoporosis: lessons for clinical practice. Joint Bone Spine. 2011;78 Suppl 2:S222-S226.

144. Venuturupalli SR and Sacks W, Review of new guidelines for the management of glucocorticoid induced osteoporosis. Curr Osteoporos Rep. 2013;11(4):357-364.

145. Glucocorticoid induced osteoporosis treatment guidelines. Chinese Journal of General Practitioners. 2006;(08):460-461.

146. Suzuki Y, Nawata H, Soen S, Fujiwara S, Nakayama H, et al., Guidelines on the management and treatment of glucocorticoid-induced osteoporosis of the Japanese Society for Bone and Mineral Research: 2014 update. J Bone Miner Metab. 2014;32(4):337-350.

147. Chopin F, Hoppé E, Morel G, Biver E, Borg S, Thomas T. Selecting the optimal treatment for glucocorticoid-induced osteoporosis. Joint Bone Spine. 2011;78 Suppl 2:S218-S221.

148. Briot K, Cortet B, Roux C, Fardet L, Abitbol V et al., 2014 update of recommendations on the prevention and treatment of glucocorticoidinduced osteoporosis. Joint Bone Spine. 2014;81(6):493-501.

149. Zhao YH and Wang MW. Progress of experimental research on prevention and treatment of osteoporosis by traditional Chinese medicine. Zhongguo Zhong Xi Yi Jie He Za Zhi. 2003;23(12):943-945.

150. Du G and Cao C. Review on experiment of traditional Chinese medicine treating to osteoporosis. Zhongguo Zhong Yao Za Zhi. 2011;36(4): 401-404.

151. Lagari VS, Levis S. Phytoestrogens in the prevention of postmenopausal bone loss. J Clin Densitom. 2013;16(4):445-449.

152. Guo AJ, Choi RC, Cheung AW, et al. Baicalin, a flavone, induces the differentiation of cultured osteoblasts: an action via the Wnt/beta-catenin signaling pathway. J Biol Chem. 2011;286(32):27882-27893.

153. Li CR, Zhang GW, Niu YB, Pan YL, Zhai YK, Mei QB. Antiosteoporosis effect of radix scutellariae extract on density and microstructure of long bones in tail-suspended sprague-dawley rats. Evid Based Complement Alternat Med. 2013;2013:753703.

154. Liu M, Xiao GG, Rong P, et al. Semen Astragali Complanati- and Rhizoma Cibotii-enhanced bone formation in osteoporosis rats. $B M C$ Complement Altern Med. 2013;13:141.

155. Zhu HM, Qin L, Garnero P, et al. The first multicenter and randomized clinical trial of herbal Fufang for treatment of postmenopausal osteoporosis. Osteoporos Int. 2012;23(4):1317-1327.

156. Watts NB, Diab DL. Long-term use of bisphosphonates in osteoporosis. J Clin Endocrinol Metab. 2010;95(4):1555-1565.

157. Schnitzer T, Bone HG, Crepaldi G, et al. Therapeutic equivalence of alendronate $70 \mathrm{mg}$ once-weekly and alendronate $10 \mathrm{mg}$ daily in the treatment of osteoporosis. Alendronate Once-Weekly Study Group. Aging (Milano). 2000;12(1):1-12.

158. Bone HG, Hosking D, Devogelaer JP, et al; Alendronate Phase III Osteoporosis Treatment Study Group. Ten years' experience with alendronate for osteoporosis in postmenopausal women. $N$ Engl J Med. 2004;350(12):1189-1199.

159. Harrington JT, Ste-Marie LG, Brandi ML, et al. Risedronate rapidly reduces the risk for nonvertebral fractures in women with postmenopausal osteoporosis. Calcif Tissue Int. 2004;74(2):129-135.

160. Whitaker M, Guo J, Kehoe T, Benson G. Bisphosphonates for osteoporosis - where do we go from here? N Engl J Med. 2012;366(22): 2048-2051.

161. Delmas PD, McClung MR, Zanchetta JR, et al. Efficacy and safety of risedronate $150 \mathrm{mg}$ once a month in the treatment of postmenopausal osteoporosis. Bone. 2008;42(1):36-42.
162. Black DM, Delmas PD, Eastell R, et al; HORIZON Pivotal Fracture Trial. Once-yearly zolendronic acid for treatment of postmenopausal osteoporosis. N Engl J Med. 2007;356(18):1809-1822.

163. Chesnut III CH, Skag A, Christiansen C, et al; Oral Ibandronate Osteoporosis Vertebral Fracture Trial in North America and Europe (BONE). Effects of oral ibandronate administered daily or intermittently on fracture risk in postmenopausal osteoporosis. J Bone Miner Res. 2004;19(8):1241-1249.

164. Chesnut CH 3rd, Silverman S, Andriano K, et al. A randomized trial of nasal spray salmon calcitonin in postmenopausal women with established osteoporosis: the prevent recurrence of osteoporotic fractures study. PROOF Study Group. Am J Med. 2000;109(4):267-276.

165. Cauley JA, Robbins J, Chen Z, et al; Women's Health Initiative Investigators. Effects of estrogen plus progestin on risk of fracture and bone mineral density: the Women's Health Initiative randomized trial. JAMA. 2003;290(13):1729-1738.

166. Simon JA, Wehren LE, Ascott-Evans BH, Omizo MK, Silfen SL, Lombardi A. Skeletal consequences of hormone therapy discontinuance: a systematic review. Obstet Gynecol Surv. 2006;61(2):115-124.

167. Delmas PD, Ensrud KE, Adachi JD, et al; Mulitple Outcomes of Raloxifene Evaluation Investigators. Efficacy of raloxifene on vertebral fracture risk reduction in postmenopausal women with osteoporosis: four-year results from a randomized clinical trial. J Clin Endocrinol Metab. 2002;87(8):3609-3617.

168. Ettinger B, Black DM, Mitlak BH, et al. Reduction of vertebral fracture risk in postmenopausal women with osteoporosis treated with raloxifene: results from a 3-year randomized clinical trial. Multiple Outcomes of Raloxifene Evaluation (MORE) Investigators. JAMA. 1999;282(7):637-645.

169. Nelson HD, Smith ME, Griffin JC, Fu R. Use of medications to reduce risk for primary breast cancer: a systematic review for the U.S. Preventive Services Task Force. Ann Intern Med. 2013;158(8):604-614.

170. Cummings SR, San Martin J, McClung MR, et al; FREEDOM Trial. Denosumab for prevention of fractures in postmenopausal women with osteoporosis. $N$ Engl J Med. 2009;361(8):756-765.

171. Delmas PD. Clinical potential of RANKL inhibition for the management of postmenopausal osteoporosis and other metabolic bone diseases. J Clin Densitom. 2008;11(2):325-338.

172. Watts NB, Lewiecki EM, Miller PD, Baim S. National Osteoporosis Foundation 2008 Clinician's Guide to Prevention and Treatment of Osteoporosis and the World Health Organization Fracture Risk Assessment Tool (FRAX): what they mean to the bone densitometrist and bone technologist. J Clin Densitom. 2008;11(4):473-477.

173. Neer RM, Arnaud CD, Zanchetta JR, et al. Effect of parathyroid hormone (1-34) on fractures and bone mineral density in postmenopausal women with osteoporosis. N Engl J Med. 2001;344(19):1434-1441.

174. Baron R, Hesse E. Update on bone anabolics in osteoporosis treatment: rationale, current status, and perspectives. J Clin Endocrinol Metab. 2012;97(2):311-325.

175. Meunier PJ, Roux C, Seeman E, et al. The effects of strontium ranelate on the risk of vertebral fracture in women with postmenopausal osteoporosis. N Engl J Med. 2004;350(5):459-468.

176. Reginster JY, Seeman E, De Vernejoul MC, et al. Strontium ranelate reduces the risk of nonvertebral fractures in postmenopausal women with osteoporosis: Treatment of Peripheral Osteoporosis (TROPOS) study. J Clin Endocrinol Metab. 2005;90(5):2816-2822.

177. Pinkerton JV, Dalkin AC. Combination therapy for treatment of osteoporosis: a review. Am J Obstet Gynecol. 2007;197(6):559-565.

178. Wu X, Pang L, Lei W, et al. Inhibition of Sca-1-positive skeletal stem cell recruitment by alendronate blunts the anabolic effects of parathyroid hormone on bone remodeling. Cell Stem Cell. 2010;7(5):571-580.

179. Finkelstein JS, Wyland JJ, Lee H, Neer RM. Effects of teriparatide, alendronate, or both in women with postmenopausal osteoporosis. J Clin Endocrinol Metab. 2010;95(4):1838-1845. 
180. Black DM, Greenspan SL, Ensrud KE, et al; PaTH Study Investigators. The effects of parathyroid hormone and alendronate alone or in combination in postmenopausal osteoporosis. N Engl J Med. 2003;349(13): 1207-1215.

181. Muschitz C, Kocijan R, Fahrleitner-Pammer A, Lung S, Resch H. Antiresorptives overlapping ongoing teriparatide treatment result in additional increases in bone mineral density. J Bone Miner Res. 2013; 28(1):196-205

182. Buckland J. Osteoporosis: Teriparatide and denosumab: two drugs are better than one!. Nat Rev Rheumatol. 2013;9(7):383.

183. Tsai JN, Uihlein AV, Lee H, et al. Teriparatide and denosumab, alone or combined, in women with postmenopausal osteoporosis: the DATA study randomised trial. Lancet. 2013;382(9886):50-56.
184. Miller PD, Chines AA, Christiansen C, et al. Effects of bazedoxifene on BMD and bone turnover in postmenopausal women: 2-yr results of a randomized, double-blind, placebo-, and active-controlled study. J Bone Miner Res. 2008;23(4):525-535.

185. Clarke BL. Anti-sclerostin antibodies: utility in treatment of osteoporosis. Maturitas. 2014;78(3):199-204.

186. Baron R, Kneissel M. WNT signaling in bone homeostasis and disease: from human mutations to treatments. Nat Med. 2013;19(2): 179-192.

187. Guan M, Yao W, Liu R, et al. Directing mesenchymal stem cells to bone to augment bone formation and increase bone mass. Nat Med. 2012;18(3):456-462.

\section{Clinical Interventions in Aging}

\section{Publish your work in this journal}

Clinical Interventions in Aging is an international, peer-reviewed journal focusing on evidence-based reports on the value or lack thereof of treatments intended to prevent or delay the onset of maladaptive correlates of aging in human beings. This journal is indexed on PubMed Central, MedLine,

\section{Dovepress}

CAS, Scopus and the Elsevier Bibliographic databases. The manuscript management system is completely online and includes a very quick and fair peer-review system, which is all easy to use. Visit http://www.dovepress. com/testimonials.php to read real quotes from published authors. 